\title{
É possível uma gestão pública de governança transnacional no século 21?
}

\author{
Maria Alice Nunes Costa \\ Universidade Federal Fluminense (UFF) \\ Wagner dos Santos Ramos \\ Universidade Federal Fluminense (UFF)
}

José Eduardo Pereira Filho

Faculdades São José (FSJ)

Daniela Juliano Silva

Universidade Federal Fluminense (UFF)

Mariana Devezas R. M. de Menezes

Universidade Federal Fluminense (UFF)

Este artigo tem por objetivo central analisar acerca do dilema da implantação e do desenvolvimento de uma gestão pública de governança transnacional para o século 21 , tendo como base uma pesquisa documental e bibliográfica. Esse dilema se refere às futuras escolhas econômicas e políticas sustentáveis ao bem-estar do planeta, da coletividade, dos seres urbanos e dos indivíduos. Existem inúmeras dificuldades práticas de se instituir uma governança em nível transnacional. Contudo, somente uma discussão nessa escala poderá superar as limitações que invocam a noção de soberania nacional como instância monística, na resolução dos problemas sociais que são de amplitude e similaridade global. Este artigo apresenta uma breve trajetória histórica do papel do Estado na modernidade ocidental e alguns desafios para o atual cenário da gestão pública no futuro vindouro. A ideia é propor a superação da polarização entre responsabilidade individual e a responsabilidade coletiva capturada pelo Estado, típica do pensamento moderno. Por meio da imaginação epistemológica, propomos a desconstrução das antigas concepções de nação e de soberania, para alcançarmos uma proposta exequível de gestão pública direcionada a ações coletivas de governança transnacional, próprias para o século 21 , tendo também como suporte analítico categorias como redes sociais e desenvolvimento territorial.

Palavras-chave: administração pública, governança, gestão de políticas públicas, poder, relações internacionais, direito internacional público

[Artigo recebido em 20 de maio de 2015. Aprovado em 3 de maio de 2016.] 


\section{¿Es posible una gestión pública transnacional del gobierno en el siglo 21?}

En este artículo se pretende acercar la reflexión sobre el dilema de la implementación y el desarrollo de la gestión pública de la gobernanza transnacional para el siglo 21. Este dilema es cuanto a futuras decisiones de política económica y sostenible para el bienestar del planeta, los seres, y los individuos urbanos colectivos. Reconocemos las dificultades prácticas para establecer un gobierno transnacional. Sin embargo, sólo la discusión en esta escala puede superar las limitaciones que invocan la noción de soberanía nacional la instancia monista, en la resolución de los problemas sociales son de amplitud y similitud global. Elaboramos una breve reseña histórica de la función del Estado en la modernidad occidental y presentamos algunos desafíos a la situación actual de la gestión pública. La idea es proponer superar la polarización entre la responsabilidad individual y la responsabilidad colectiva capturada por el Estado, típico del pensamiento moderno. Intentamos, a través de una imaginación epistemológica, deconstruir las viejas concepciones de la nación y el sentido de la soberanía, para lograr una propuesta viable para la gestión pública dirigida a las acciones colectivas de la gobernanza transnacional, apropiadas al siglo 21 , teniendo también como soporte analítico categorais como redes sociales y desarrollo territorial.

Palabras clave: administración pública, gobernanza, gestión de políticas públicas, poder, relaciones internacionales, derecho internacional público

\section{Is it possible a transnational public management governance in the 21st century?}

This article aims to bring a reflection on the dilemma of implementation and the development of a public management of transnational governance for the twenty-first century. This dilemma concerning future economic and sustainable policy choices to the welfare of the planet, the collective, urban beings and individuals. We recognize the practical difficulties to establish a transnational governance. However, only a discussion on this scale can overcome the limitations that invoke the notion of national sovereignty as monistic instance, in the resolution of social issues that are of global scope and similarity. We elaborate a brief historical background of the state's role in Western modernity and present some challenges to the current situation of public management. The idea is to propose overcoming the polarization between individual responsibility and collective responsibility captured by the state, typical of modern thought. We try, through an epistemological imagination, deconstruct the old conceptions of nation and sense of sovereignty, to achieve a workable proposal for public management directed the collective actions of transnational governance are fit for the twenty-first century.

Keywords: public administration, governance, public policy management, power, international relations, public international law 


\section{Introdução}

Busca-se trazer no bojo deste artigo a análise sobre os possíveis dilemas da implantação e do desenvolvimento de uma governança efetiva e de alcance transnacional, para o século 21 . Tais dilemas referem-se às possíveis escolhas econômicas e políticas que devem ser sustentáveis ao bem-estar do planeta, da coletividade, dos seres urbanos e dos indivíduos. Ainda que desde logo sejam reconhecidas as dificuldades práticas de se instituir uma governança transnacional, somente uma discussão neste nível poderá superar as limitações que, invariavelmente, invocam a noção de soberania nacional, como uma instância final. Nesse sentido, é preciso reforçar a necessidade de desconstrução ou revisão das clássicas concepções de nação e, especialmente, da percepção de soberania, para pensarmos na elaboração de uma estratégia de gestão pública e de políticas públicas transnacionais, próprias para o século 21.

Desde os anos 1970, os fortes ventos de mudança passaram a influenciar o modelo de gestão pública realizada, quase que exclusivamente, pela mão do Estado. Mesmo em países que possuíam uma rede razoavelmente estruturada de proteção social, o ajuste estrutural, dos anos 1980, terminou por reestruturar e desorganizar os direitos sociais conquistados ao longo do século 21.

No final dos anos 1980, intelectuais-tecnocratas, aliados ao Consenso de Washington e inspirados no modelo inglês, elaboraram o receituário de Reforma do Estado a ser seguido internacionalmente, em especial, na América Latina e Caribe.

No Brasil, nos anos 1990, uma reengenharia no Estado foi praticamente imperiosa, sem muitos debates na sociedade civil ou no Parlamento. Havia um relativo consenso de que as coisas precisavam mudar. Parece paradoxal com a redemocratização em curso, mas as mudanças ocorreram sem grandes conflitos e de modo bem diferente quando comparadas aos debates acirrados sobre o ajuste fiscal e a reforma política que estamos a assistir, em 2015.

Em 1995, o Governo Presidencial de FHC criou um ministério para tal reforma (Ministério da Administração Federal e Reforma do Estado). Dessa forma, passamos a observar um planejamento estratégico-gerencial para a construção de uma nova forma de gestão pública, que transformasse a antiga visão estadocêntrica em uma nova racionalidade para incrementar a força e a eficácia do Estado - a visão sociocêntrica (GRAU, 1998).

Nesse sentido, passamos a observar mais nitidamente, no discurso dos agentes centrais do Estado e demais instituições hegemônicas, o aumento da importância da participação da sociedade civil na busca de melhores condições de vida e bemestar, ao lado da valorização da eficácia e eficiência na gestão pública. 
A nova configuração institucional sociocêntrica foi elaborada com a expectativa de que a transferência de responsabilidade do Estado para outras instâncias sociais poderia tornar o Estado mais eficaz e eficiente para promover a coesão social e garantir a governabilidade, por meio da institucionalização de dispositivos de governança.

As teorias que buscaram explicar a redefinição das funções do Estado passaram a recorrer à concepção de governança (governance). O termo pretendeu ampliar o conceito estritamente econômico de gestão pública, para alcançar uma visão mais abrangente que envolvesse, interdisciplinarmente, as dimensões econômica, política e social, no sentido de aumentar a capacidade e credibilidade do governo.

O debate sobre governança surgiu a partir da necessidade da redefinição e de uma nova articulação entre Estado, mercado e sociedade civil. A crise do modelo do Estado-providência e a crise do Estado-desenvolvimentista na América Latina mostrou o esgotamento do modelo centralizador do Estado. Surgiu a exigência de se pensar modelos alternativos de organização política que assegurassem a governabilidade no âmbito dos países da Organização para a Cooperação Econômica e Desenvolvimento (OCDE).

O incentivo à participação societária foi resultado do entendimento de que a interdição centralizadora do Estado era insuficiente ou ineficaz para controlar a ação coletiva dos movimentos sociais que emergiam por justiça social e pela incapacidade financeira de oferecer infraestrutura econômica. Dessa forma, a máquina burocrática abriu canais de comunicação e criou novas institucionalidades jurídicas que promovessem a participação social e as parcerias público-privada (PPP).

Três fatores convergiram para influenciar a adoção da estratégia de governança na gestão de políticas públicas no Brasil (COSTA, 2011):

1. Constrangimento e Concertação Internacional. As alterações do modelo de Estado centralizador ganhou preponderância na agenda pública com a ideia da estruturação de um Estado mínimo, liberando as forças do mercado e "libertando" a energia da sociedade para arcar com a função social, seguindo valores de corresponsabilidade, solidariedade voluntária, da autoajuda e da ajuda mútua. A natureza da intervenção centralizadora estatal e os caminhos da reforma do Estado transformaram-se em temas hegemônicos na agenda brasileira.

2. Mobilização Social. Com o crescimento dos problemas econômicos sociais, movimentos sociais se formalizaram em ONGs reivindicando direitos de cidadania em contexto de democratização do País. Surgiu uma pluralidade de atores sociais disputando e convergindo seus próprios interesses diante 
das incertezas e da precariedade social. O Banco Mundial aumentou a destinação de verbas para organizações não governamentais nos anos 1980 com o objetivo de cooptar as lideranças sociais e amortecer os ideários de luta que emergiam. Assim, ao invés de pensar a sociedade como um todo estrutural e coletivo, as organizações sociais passaram a elaborar projetos pulverizados em parceria com o Estado, empresas e fundações mediante a força relativa, capital social e informações disponíveis de grupos que tivessem o "mérito" para assegurar a negociação nessa parceria.

3. Qualidade Total e Responsabilidade Social Corporativa. Surgiu uma nova percepção empresarial da questão social, ainda que não generalizada. 0 aumento da competição internacional impulsionou padrões de desempenho produtivo e tecnológico para diferenciar as empresas no mercado. 0 conhecimento e a educação passaram a ser considerados como fatores fundamentais para o aumento da produtividade. Um laboratório de ideias se instalou nas grandes empresas para buscar tecnologias inovadoras e formas de gestão que trouxessem maior produtividade com menor custo ou com valor social agregado. Foram criadas diretrizes internacionais de qualidade nos serviços e produtos e sobre responsabilidade social das empresas. Essas diretrizes possibilitaram às empresas optarem por ser auditadas consensual e voluntariamente, como forma de demonstrarem seu diferencial no mercado como empresas socialmente responsáveis, quando adotam códigos de ética, padrões de qualidade e respeito aos direitos humanos.

Esses três fatores associados convergiram de maneira dinâmica, influenciando as atuais condutas do ato de governar. Nesse sentido, tendo passado duas décadas da Reforma do Estado no Brasil (1995-2015), este artigo buscará construir uma reflexão que vá além da preocupação com uma gestão de políticas públicas centrada no Estado nacional. Pretende-se incitar os leitores, em particular os gestores que atuam com as complexidades deste novo século, a pensarem por meio da imaginação epistemológica como política a questão dos principais problemas que afetam a contemporaneidade, sugerindo uma alteração de escala para fazer frente aos enfrentamentos gerenciais nacionais. Problemas esses que são estruturais e ocorrem em escalas transfonteiriças: desigualdades e injustiças sociais, conflitos e insegurança urbana.

O processo de globalização não pode ser reduzido à dimensão econômica, na medida em que há outros processos de globalização que se interligam, com sérias implicações no âmbito político, social e cultural de muitos países e que sucedem de maneira similar. Os que mais estão suscetíveis aos impactos negativos da globalização são os países pobres ou em desenvolvimento. 
Este artigo tem como base metológica uma breve revisão bibliográfica em torno do tema e das categorias em questão, visando identificar as principais visões dos autores e pensadores que analisam de modo direto e indireto a dinâmica da gestão e governança transnacionais, recuperando, assim, conceitualmente o referido tema.

Buscou-se também uma pesquisa documental visando ao registro das visões e acontecimentos históricos recentes dos principais organismos multilaterais que são centrais para entender, no campo político, como está a discussão do tripé da governança, transnacionalidade e soberania.

No primeiro momento, iremos fazer uma breve discussão dos conceitos de redes sociais e desenvolvimento territorial. No momento seguinte, trazemos à tona o debate em torno das políticas públicas e da governança. A seguir, discutiremos a dinâmica território-soberania, associando a sustentabilidade à governação transnacional. Finalizamos com o debate sobre a viabilidade de uma gestão pública em uma escala transnacional.

\section{Redes sociais e desenvolvimento territorial}

Atualmente, as redes se tornaram a principal forma de coordenação das relações sociais sob o capitalismo. Domingues (2002) acredita que elas tendem a responder à atual complexidade social, como meio de tecer a solidariedade entre os membros da sociedade, na medida em que "solidariedade significa estar aberto ao outro, atingir alguém, engajar-se com outras pessoas, com outras coletividades, ao menos em certo grau em seus próprios termos" (DOMINGUES, 2002, p. 240). Por essa razão, Domingues acredita que a coordenação por redes pode gerar bons frutos quando induzir a relações colaborativas, democráticas e emancipatóriais.

As redes podem ser compreendidas como um complexo de organizações conectadas umas com as outras, por recursos dependentes e distintos uns dos outros. Desse modo, as redes podem ter diferentes estruturas e intensidades, pelo fato de envolverem uma conexão de interesses interdependentes, garantindo que os atores sociais estabeleçam sinergia, assim como também expressem seus conflitos e divergências.

O trabalho em redes tanto pode possibilitar a adequação dos planos de desenvolvimento quanto beneficiar as empresas, que podem reduzir os custos das transações por meio de laços cooperativos e de confiança entre agências públicas, privadas e internacionais.

Os analistas de redes tentam descrever esses padrões e compreender como as estruturas de redes influenciam o comportamento social e produzem mudança. Suas descrições estão baseadas em conceitos de laços (ties), conectando nódulos 
(nodes) em um sistema social - laços que conectam pessoas, grupos, organizações. Dessa maneira, as redes sociais de solidariedade se organizam para buscar o enfrentamento da insegurança econômica e da ineficiência dos serviços públicos (WELLMAN, 1991).

Para Norbert Lechner (1997), as redes são um novo conceito, crucial para a compreensão de gestão pública descentralizada. Norbert Lechner chamou de coordenação social por redes um arranjo organizacional composto por vários indivíduos ou instituições que estão vinculados em torno de um projeto específico. A coordenação dos interesses individuais e coletivos, em rede, requer contínuas negociações que não se limitam a uma troca de benefícios entre os participantes. A coordenação por redes retoma a ideia de arena permeada de conflitos, negociações e consenso, na qual deve haver certo grau de equilíbrio entre sociedade e Estado. Assim, passam a coexistir duas tendências: de um lado, a diversidade e o fortalecimento da sociedade e, de outro, o redimensionamento da ação do Estado, gerando mudanças de longo alcance na política.

As redes disciplinam a competência, inibindo suas dinâmicas destrutivas e canalizando as expectativas recíprocas. Elas podem operar nos níveis internacional, nacional, regional e local e referir-se à resolução de muitos problemas. Podem auxiliar não somente a articulação de diferentes atores, às vezes antagônicos, mas também a execução efetiva das decisões tomadas. Essa corresponsabilidade na execução das medidas acordadas é de particular relevância, dada a debilidade das capacidades estatais de regulação.

Evidentemente que não se pode generalizar que a coordenação por redes assegura por si só o processo democrático, pois a população pode ter informações assimétricas, pois, quando não organizada, não tem acesso às redes. Além disso, sabemos que os próprios representantes do Estado, ao invés de fazer valer os "interesses gerais", podem não se dispor a propor uma deliberação democrática prévia acerca do bem comum. Em suma, não existe uma vinculação intrínseca entre a coordenação mediante redes e as instituições democráticas. Pelo contrário, a representação funcional por meio de redes e a representação territorial típica das instituições democráticas podem chegar a serem canais paralelos, quando não contraditórios.

Prevendo tais riscos, Lechner propõe que a coordenação por redes se sustente a partir da composição do triângulo habermasiano, ou seja: do poder comunicativo (eleições, parlamento e opinião pública); do poder social (interesses organizados); e do poder administrativo (governo, tribunais de justiça e administração pública).

Segundo Habermas, com o esgotamento das energias utópicas de uma sociedade do trabalho, a proteção contra os imperativos do sistema exige uma "nova partilha 
do poder" dentre os três recursos: o dinheiro, o poder e a solidariedade. O autor considera a existência de três arenas políticas. A primeira no âmbito estatal; a segunda, no nível de atores anônimos e coletivos; a terceira arena, localizada no mundo da vida, onde não se luta diretamente por dinheiro ou poder, mas por definições ideológicas e políticas. Interagindo comunicativamente, "todo projeto que quiser redirecionar forças em favor do exercício solidário do governo tem de mobilizar a arena inferior ante as duas de cima" (HABERMAS, 1987).

$\mathrm{Na}$ concepção habermasiana, a solidariedade social pode desenvolver-se com base em amplos espaços públicos autônomos e em procedimentos de formação democrática de opinião e vontades políticas, institucionalizados em termos de Estado de Direito. Ela deve ser capaz de, por meio do Direito, afirmar-se também contra os poderes econômico e administrativo.

Para Habermas, a instância geradora de poder legítimo é a esfera pública: dimensão da sociedade onde se dá o intercâmbio discursivo. É o espaço de debate público, visto como arena de discurso autônoma, local onde se realiza a interação intersubjetiva de cidadãos conscientes, solidários e participativos. A autonomia do espaço público revaloriza o primado da comunidade e da solidariedade, possibilitando a libertação da sociedade civil dos imperativos sistêmicos, isto é, dos controles burocráticos do Estado e das imposições econômicas do mercado.

Em relação à internacionalização de redes na governança global, Araújo (2011) afirma que a governança global vem se movimentando por uma nova gama de atores sociais atuando em redes de cidades. Para a autora, as redes de cidades são uma nova forma de governança inserida num contexto de governança global, na medida em que as ações das cidades têm importante relevância internacional. Representam a nova realidade mundial e refletem em suas próprias estruturas os inovadores modos de pensar e de interagir acerca dos problemas citadinos mundiais. Segundo a autora, as unidades subnacionais, governos locais, empresas e organizações não governamentais passaram a ser entendidos como objetos centrais de análise e de atuação internacional, constituindo-se assim a chamada paradiplomacia.

Portanto, as cidades são, por excelência, lugares de máxima intensidade relacional. São expressão de criação do novo, de cosmopolitismo, lugar exato das capacidades incontornáveis e do inesperado. Nesse sentido, podemos vê-las como promotoras de densidades territoriais que são fatores relevantes das dinâmicas que organizam o mundo (REIS, 2004).

Para o autor, cada país, região, território ou cidade são sistemas urbanos de peso diferente, mas, ainda assim, significativo no contexto dos respectivos espaços. Asseguram massa (dimensão e poder) e conectividade (capacidade relacional física, 
econômica e social) e representam "corredores" de desenvolvimento transnacional. Portanto, é a formação e o uso do capital relacional gerado territorialmente que evidencia qual é a natureza do sistema urbano e o seu papel nos contextos local, infranacional, nacional ou transnacional.

Ao mencionarmos o papel das cidades na governança global, podemos estabelecer uma relação entre a gestão de políticas públicas e desenvolvimento territorial. Segundo Dallabrida (2010), o esquema bipolar de desenvolvimento de uma só direção - do local para o global - deve incluir o desafio de se evoluir para um esquema multiescalar e multidirecional de desenvolvimento, revelando a complexidade da governança global.

Portanto, ao relacionarmos redes sociais com desenvolvimento territorial, precisamos ter como objetivo a necessidade de envolver diferentes visões de mundo em escala global, tanto estatais como de atores sociais organizados e em situação de exclusão das instâncias internacionais, até então de locus privilegiado. Importa ressaltar que os conflitos de interesses são naturais, no sentido de fazer parte da vida social e, quando ocorrerem em processos e dimensões institucionais democráticas e dialógicas, podem conter o embrião para a construção de alternativas de regulação mundial para efetivo e concertado desenvolvimento territorial em escala transnacional.

A seguir, iremos analisar a governança sob a ótica das políticas públicas em um contexto mundial de alta complexidade.

\section{Governança e políticas públicas}

O sociólogo português Boaventura de Sousa Santos tem demonstrado em sua trajetória acadêmica que, diante da iniquidade do mundo e do colapso social em que vivemos, a única saída é a luta do movimento democrático transnacional. Em seu breve artigo para a Revista Visão (2000), ele cita a proposta do economista Jeffrey Sachs de substituição do Banco Mundial por uma agência de desenvolvimento mundial. Para Boaventura, essa é uma grande ideia, na medida em que, por detrás dessas instituições multilaterais, estão os países ricos que as usam somente para defender as suas próprias populações da revolta e da ameaça dos pobres e esfomeados do mundo.

Existe um relativo consenso de que uma política pública (policy) para ser efetiva e eficiente deve ampliar o leque de atores consultados. Nesse sentido, atualmente, e cada vez mais de modo crescente, a formulação de políticas públicas não se reduz ao papel do Estado e dos governos. Muitas têm sido produzidas por determinadas 
racionalidades e leituras da realidade social de um conjunto diversificado de atores sociais que se entrecruzam: pela lógica do Estado; pelos interesses das corporações e empresas; e por cidadãos e atores em situação de "exclusão". Podemos entender, de acordo com Isabel Guerra, que hoje

as políticas públicas são o resultado de processos de negociação em contextos de poder desiguais, funcionando como mecanismos de regulação social e de governança (...) não são fatores de dominação ou de emancipação, já que contém simultaneamente tendências hegemônicas e contrahegemônicas, não sendo estádios de desenvolvimento, mas dimensões inerentes às formas de constituição da vida social (GUERRA, 2000, p. 53).

Cada vez mais se reconhece que a gestão de políticas públicas é determinada por processos múltiplos, vinculados à dinâmica das relações de poder, às características das instituições políticas e ao tipo de relações existentes entre Estado e multistakeholders. É pressuposto que o alargamento da participação social na definição dos objetivos de uma política facilitará a utilização de esforços e recursos. Os atores envolvidos poderão identificar, com mais facilidade, as prioridades e as suas obrigações em todo o processo, compartilhando com o poder público a tomada de decisão. Muitos acreditam que o exercício da governança local e subnacional aumenta a legitimidade do governo eleito, pois as políticas públicas são desenvolvidas com a utilização do consenso de diferentes forças políticas envolvidas.

Essa percepção, no Brasil desde os anos 1990, está associada à democracia emergente, onde a participação social passou a ser considerada como prioridade para a implementação de políticas sociais, e referendada recentemente pelo Decreto Federal instituído em 23 de maio de 2014 (DECRETO n 8.243/2014, Política Nacional de Participação Social).

A partir dos anos 1980 no Brasil, quando se deu o movimento de retração estatal, o poder, antes localizado prioritariamente no Estado, deu lugar a um poder difuso, que se estendeu por uma rede de relações e por campos setoriais, como grupos de mulheres, de jovens, grupos étnicos, sexistas, ambientalistas, entre outros. As iniciativas da sociedade civil apontaram para o surgimento de uma nova cultura política, uma vez que as práticas sociais passaram a ser orientadas por um novo nível de condutas, normas e valores em relação ao interesse público.

O Instituto Brasileiro de Geografia e Estatística (IBGE) e o Instituto de Pesquisa Econômica Aplicada (Ipea), em parceria com a Associação Brasileira de Organizações Não Governamentais (Abong) e o Grupo de Institutos, Fundações e Empresas (Gife), realizaram a pesquisa intitulada As fundações privadas e associações sem fins 
lucrativos no Brasil 2002, conhecida pela sigla Fasfil. Foi publicada em 2004, pela Associação Brasileira de Organizações Não Governamentais ${ }^{1}$.

No geral, as Fasfil são relativamente novas, pois cerca de dois terços delas (62\%) foram criadas a partir da década de 1990. A cada década se acelerou o ritmo de crescimento. As que surgiram nos anos 1980 foram $88 \%$ mais numerosas do que aquelas que surgiram nos anos de 1970; esse percentual é de $124 \%$ para as que foram criadas na década de 1990 em relação à década anterior. De acordo com a pesquisa, foi expressivo o crescimento das Fasfil entre os anos 1996 e 2002, em que o número quase dobrou, passando de 105 mil para 276 mil, correspondendo a um aumento de 157\%. Apesar desse crescimento ter sido verificado em todas as áreas de atuação, merecem destaque as associações ligadas ao meio ambiente e defesa de direitos humanos que quadriplicaram o número de entidades (309\% e 303\%, respectivamente), e as associações patronais e profissionais que mais que duplicaram (252\%).

Para Manuel Castells (2001), a crescente falta de operacionalidade do Estado para resolver os problemas no contexto da globalização criou uma crise de confiança e legitimidade em boa parte da população em quase todos os países. A partir desse fato, surgiu uma nova forma de Estado que Castells denomina de Estadorede. Essa fórmula é o sucedâneo do Estado nacional em crise com problemas de administração e gestão pública. Para que o Estado resgatasse a sua legitimidade, ele precisou então adaptar a sua forma de regulação, pois - como afirmou Castells - "a pior forma de descontrole é manter vigente o que não se pode aplicar" (2001, p. 156). Ele a define da seguinte forma:

O Estado que denomino de Estado-rede se caracteriza por compartilhar a autoridade (ou seja, a capacidade institucional de impor uma decisão) através de uma série de instituições. Uma rede, por definição, não tem centro e sim nós, de diferentes dimensões e com relações internodais que são frequentemente assimétricas. Mas, enfim, todos os nós são necessários para a existência da rede. Assim, o Estado-nação se articula cotidianamente na tomada de decisões com instituições supranacionais de distintos tipos e em distintos âmbitos (...) também funcionam em rede, nessa mesma rede, instituições regionais e locais (...) dela participam organizações não governamentais (...) que se conectam com esta rede interinstitucional, feita tanto de negociação como de decisão, de compromisso como de autoridade, de informação como de estratégia (CASTELLS, 2001, p. 164).

\footnotetext{
${ }^{1} \mathrm{O}$ estudo foi realizado a partir do Cadastro Central de Empresas do IBGE, para o ano de 2002, em que se cobriu o universo das organizações inscritas no Cadastro Nacional de Pessoa Jurídica (CNPJ), do Ministério da Fazenda, que, em 2002, declararam ao Ministério do Trabalho e Emprego exercer atividade econômica no território nacional. O cadastro abrange tanto entidades empresariais, como órgãos da administração pública e instituições privadas sem fins lucrativos.
} 
Nesse cenário de redes, o desenho das políticas públicas tem se ampliado e se tornado mais complexo. O estabelecimento de redes de parcerias com o setor privado, organizações sociais e comunidade tem sido uma das formas de o Estado gerir a questão social, por meio da governança.

Nesse sentido, visualizamos a estratégia da governança como um novo estilo de governar em um cenário democrático, caracterizado por diferentes graus de interação e cooperação entre o Estado e atores não estatais, constituindo redes de decisão conjuntas, diferente do modelo de controle hierárquico. Desse modo, o processo de formulação e implantação de projetos sociais e de políticas públicas pode ocorrer por meio da cooperação inter e intrainstitucional, e entre atores públicos e privados, numa estrutura de redes.

Portanto, o conceito de governança se insere no contexto atual das transformações das funções públicas exercidas pelo Estado. Conclama-se, pois, por uma agenda compartilhada direcionada ao desenvolvimento socioeconômico e à coesão social.

O desafio da reforma do Estado produziu profusa literatura sobre o papel do Estado. Alguns autores que se dedicaram a recuperar a origem histórica da crise do Estado e analisar suas características se esforçaram por oferecer diagnósticos e soluções para os problemas encontrados (DINIZ, 1997; BRESSER PEREIRA, 1998; Grau, 1998; Rosanvallon, 1998; CASTElLS, 2001; SANTOS, 1999; entre outros.).

A forma qualificada como burocrática de administração centralizada no Estado foi criticada por inúmeros intelectuais e, principalmente, por agências multilaterais de financiamento, por ser um tipo de gestão rígida e ineficiente do aparato público (COSTA, 2011).

As teorias que buscaram explicar a redefinição das funções do Estado vieram recorrendo, desde os anos 1990, à concepção de governança (governance). O termo governance tem por base os estudos seminais de Ronald Coase, publicados em 1937, The nature of the firm (COASE, 1991). Esses estudos foram posteriormente aperfeiçoados por Oliver Williamson (1975). A governança, de acordo com as análises de Coase e reforçadas por Williamson, designaria os dispositivos operacionalizados pela firma para conduzir coordenações eficazes que tangem a dois registros: os protocolos internos, quando a firma desenvolve suas redes e questiona as hierarquias internas; e os contratos e as aplicações de normas, quando ela se abre à terceirização.

Para Coase e Williamson (1991), as trocas ou transações podem organizar-se em duas direções: o mercado ou as organizações (denominadas de hierárquicas por Williamson). O mercado, para ser eficaz, deve responder a uma condição de atomicidade; é, portanto, uma forma organizacional fragmentada. A complexidade dessas trocas gera custos. A grande firma impõe-se como um meio para reduzir esses custos de transação. 
Registre-se que o uso do termo governance, importado do mundo da empresa para descrever protocolos de coordenação diferentes dos mercados, seria aplicado posteriormente ao mundo do poder e das organizações locais, cujas variações em termos de contextos são fundamentais.

O debate sobre esse tema ressurgiu, nos anos noventa, a partir da necessidade de uma redefinição da articulação entre Estado, empresas e sociedade civil no âmbito dos países da Organização para a Cooperação Econômica e Desenvolvimento (OCDE) e da crise do Estado desenvolvimentista na América Latina. O esgotamento do modelo de Estado centralizador trouxe a exigência de se pensar modelos alternativos de organização política que assegurassem a governabilidade desses Estados (COSTA, 2011).

O termo governance foi reintroduzido no debate público internacional em 1992 pelo Banco Mundial². E o Fundo Monetário Internacional passou a legitimar também suas orientações por esse conceito. A noção de boa governação (good governance), do Banco Mundial, vem intrinsecamente associada à capacidade governativa e passa a ser requisito indispensável para um desenvolvimento sustentável, conceito que incorpora ao crescimento econômico a equidade social e os direitos humanos (WORLD BANK, 1992). É no referido momento que se dá a transferência ou inclusão da categoria governança do meio corporativo para o segmento governamental e/ou estatal.

No âmbito das Nações Unidas, o Programa das Nações Unidas para o Desenvolvimento (PNUD) define governance enquanto exercício de autoridade política, econômica e administrativa na gestão dos problemas coletivos nos diferentes níveis. A governance corresponderia ao conjunto complexo de mecanismos, processos e instituições, por meio dos quais cidadãos e movimentos sociais articulam seus interesses, exercem seus direitos e cumprem seus deveres, bem como solucionam as diferenças (United Nations DeVelopment Program/ UNDP/PNUD, 1997).

A boa governação (sound governance) deve ser participativa, transparente, eficaz, equitativa e fundada na lei. Segundo o PNUD, a governance engloba o Estado, a sociedade civil e o setor privado, devendo ser entendida em três perspectivas principais: a) governança econômica - que compreende processos de tomada de decisão que afetam atividades econômicas nacionais e internacionais, b) governança política - que se refere à concepção e à implementação de políticas de desenvolvimento, e c) governança administrativa - que inclui sistemas de gestão pública (United Nations DeVelopment Program/Undp/Pnud, 1997).

\footnotetext{
${ }^{2}$ Para o Banco Mundial, a definição de governance consiste "na maneira pela qual o poder é exercido na gestão dos recursos econômicos e sociais de um país com vistas ao desenvolvimento." (WORLD BANK, "Governance and Development", 1992, p. 1-3).
} 
Nesse sentido, quando o PNUD trata de governança democrática, ele se refere fundamentalmente à capacidade do governo e de outros atores políticos de gerir o objetivo sistêmico da democracia, do mercado e da equidade.

Para Boaventura de Sousa Santos (2005), essa governance é um modo de regulação social pós estatal, inserida na matriz neoliberal da globalização hegemônica, que ele denomina de matriz de governação neoliberal.

Para Santos, essa matriz é resultado de várias perspectivas quanto à crise do Estado. Segundo o autor, a compreensão da crise da legitimidade, nos anos 1970, pautava-se na ideia de que a crise era derivada do descontentamento dos grupos excluídos e, portanto, a solução era transformar o Estado e aumentar a participação popular. Nos anos 1980, a crise da legitimidade foi convertida em crise da governabilidade, na medida em que o Estado apareceu como sobrecarregado de demandas sociais.

A matriz neoliberal precisou responder às novas demandas sociais. A solução encontrada, aliada à retração do Estado, é a de que a participação popular deve ser tolerada somente quando envolver uma concepção individualista da sociedade civil. Por essa concepção, a participação popular estaria sendo "domesticada" para não abalar as estruturas morais do capitalismo.

Para o autor, em certas circunstâncias, arranjos dessa governance podem trazer benefícios quando o Estado utilizar a energia da sociedade civil como atributo do Estado nacional ou para a construção de instituições políticas supranacionais.

Partimos do pressuposto de que um sistema de governança é composto pelo conjunto de instituições, regulamentos, dispositivos legais e convenções culturais que regem o comportamento e as relações entre diferentes atores políticos e setores sociais e econômicos.

A adoção de uma ou outra forma de governança depende e refere-se à interpretação e aos valores culturais da instituição política e da relação de seus líderes, governantes e governados, sendo as tomadas de decisão resultantes dessa correlação de forças políticas.

Dessa forma, o desenvolvimento de uma ou outra conduta da governança está condicionado à cultura política construída por meio de processo histórico e institucional (path dependence) de cada sociedade. Sendo assim, a governança estabelecida pode atuar efetivamente por meio de um processo democrático de participação igualitária ou não. Dessa forma, nuances e variedades no desempenho da governança podem ser observadas e sinalizar as variedades das democracias existentes no planeta.

Poderemos visualizar e identificar na coordenação de qualquer governança nacional três tipos de ativismo, tipificados como de baixa intensidade, de alta 
intensidade ou de um tipo híbrido de média intensidade. Todos os graus de intensidade poderão estar numa relação de causa e efeito entre os dispositivos institucionais instaurados e a cultura política contida em cada governança estabelecida. Portanto, uma boa governança transnacional, a de alta intensidade, pode vir a estabelecer um equilíbrio entre as nações, bem como entre os níveis local, regional e transnacional.

É nesse ponto que se abre uma expectativa para se discutir as desigualdades de poder entre os países.

As lideranças políticas internacionais, com legitimidade e credibilidade, podem ter um papel importante na mediação entre as expectativas nacionais e a construção do consenso coletivo internacional. A articulação dessas lideranças internacionais com instâncias institucionais globais e lideranças comunitárias nacionais, atuando de maneira interdependente e atendendo à diversidade crescente, pode permitir estruturas mais inteligentes de governança. Nos atuais níveis de complexidade de uma gestão pública, novos canais de comunicação e de formas de participação internacionais e transnacionais precisam ser inventados e reinventados, tanto dentro dos Estados e nações, como nos níveis supra e transnacional.

As opções das lideranças internacionais, as suas coalizões com corporações multinacionais e suas ações intra e supranacionais são aspectos decisivos na definição de agendas a serem implementadas no século 21 , bem como a escolha e as estratégias da forma de inserção de suas decisões no contexto internacional.

Os imperativos internos e locais não podem ser ignorados ou negligenciados. Contudo, há sempre margem para escolhas dotadas de maior ou menor interdependência, maior ou menor diálogo e criatividade. Ou, ao contrário: maior conformismo, passividade e subserviência, principalmente de países com frágeis instituições e sociedade civil, como os países mais pobres. A opção por um ou outro caminho tem consequências não desprezíveis sobre o resultado final, que se refletirá, por sua vez, na qualidade da tomada de decisões e da gestão de políticas públicas transnacionais. Portanto, é a capacidade efetiva de mobilização e de atuação coletiva virtuosa de lideranças supra e transnacional que está em causa.

A seguir, iremos analisar como têm se dado as discussões em torno da soberania em uma perspectiva transnacional.

\section{Soberania e território transnacional}

No atual cenário de ajuste global, vem à tona a capacidade política de articulação de uma agenda de gestão pública transnacional atenta à provisão de bens públicos globais, tais como a moeda de reserva, a estabilidade das 
transações comerciais e dos fluxos financeiros e a questão da escassez de energia. Cada sistema nacional e em nível global vem tentado encontrar soluções visando restabelecer o equilíbrio no mundo.

Os desiquilíbrios são globais e, na maioria das vezes, ignoramos que "o nosso mundo interdependente significa que nossos problemas não são mais apenas problemas em comum. Mas são globais. Interpenetram países e são somente abordáveis mediante uma ação concertada"3 (BERGGRUEN; GARDELS, 2013).

Em outras palavras, nota-se que o mundo atual está tão interligado que uma ação isolada no Japão não permanece restrita a seu território. Ela é capaz de causar impactos nas mais diversas localidades do globo terrestre. Tal assertiva é verdadeira tanto em se tratando de ações governamentais quanto de corporações que atuam em âmbito internacional.

Os elevados padrões de desigualdade da riqueza, das injustiças sociais, das epidemias de violências e da degradação ambiental que a humanidade vem enfrentando trazem questões complexas, sobretudo pelo fato de se impor uma agenda e uma atuação coletiva global. Portanto, estamos tratando sobre a emergência de uma gestão pública e de políticas públicas em nível transnacional, propícia para o século 21.

O conceito clássico de soberania que compreende o Estado unitário em sua forma única e apresenta o território como uma esfera unificada e com jurisdição própria parece já estar cada vez mais obsoleto e deve ser questionado por uma dupla esfera: uma de âmbito infranacional e outra de níveis supra e transnacional. Celso Fernando Campilongo (2007), alerta:

O que é "soberania" hoje? Não existe mais, entre os juristas, quem aposte cegamente nas respostas clássicas. Com a globalização econômica, o sistema social teria perdido o centro e o vértice. A fragmentação dos interesses, a pluralização dos âmbitos sociais, o pluralismo das fontes do direito e a multiplicidade de formas de autoridade, para vários juristas, teriam estilhaçado qualquer pretendente ao topo. Por isso, não são muitos os que se arriscam a responder à questão inicial (CELSO FERnANDo CAMPILONGO, 2007, p. VIII) .

Nessa trajetória epistemológica, esbarramos com problemas de ordem política e jurídica. Significa obrigatoriamente adentrarmos numa arena nebulosa, que diz respeito à soberania e supremacia estatal. Essa questão traz, em seu bojo, a existência de leis que atuam com graus variados de exigência. Resulta em custos

\footnotetext{
${ }^{3}$ Sentença proferida pelo ex-primeiro ministro britânico Gordon Brown em reunião do Conselho para o Século 21, realizado em Nova York, em março de 2011 (BERggruen; GARDELS, 2013).
} 
diferenciados, criados por um mercado de normas e certificações, em especial, aquelas exigidas aos países periféricos e semiperiféricos, do sistema do mundo capitalista que vem prejudicando a sua competitividade econômica internacional.

As ideias de "nação", "nacionalidade", e mesmo a noção de "Estado", nascidas na modernidade, serviram igualmente aos Estados para legitimar sua concepção de soberania como "nacional" e "popular". Tal concepção enfrenta seus percalços e ao se debruçar sobre o inadequado e obsoleto paradigma do velho Estado soberano, Luigi Ferrajoli afirma que

[...] essas mesmas ideias estão se voltando contra os Estados, concebidos e legitimados como instrumentos de pacificação interna e de unificação nacional. Eles, enfim, revelam não apenas as principais ameaças à paz externa, como também fontes de perigo para a paz interna e fatores permanentes de desagregação e conflito (FERRAJOLI, 2007, p. 50).

Nesse sentido, o autor propõe a superação do Estado nacional, por meio da reconstrução do Direito Internacional. Esse deve se fundar não na soberania dos Estados, mas, sim, na autonomia dos povos. Como alternativa, sugere a elaboração de um "constitucionalismo mundial", que seja capaz de oferecer garantias jurídicas às várias cartas dos direitos fundamentais já firmadas, o que atacaria a ineficácia das mesmas ${ }^{4}$.

Diante disso, o principal desafio da comunidade internacional, voltada para a construção de uma agenda de políticas públicas para uma governança transnacional, está nas limitações do Direito Internacional público em compreender a complexidade dos impactos do conceito de soberania nacional. O Direito Internacional tem se reduzido, quase que exclusivamente, à proteção da humanidade contra as guerras e o terrorismo ou na arbitragem internacional do comércio. São quase inexistentes iniciativas movidas ou guiadas para dar cabo às injustiças sociais e às desigualdades de riquezas globais. Essas são as que produzem o terrorismo.

Ao debruçarmos sobre o conceito de soberania, importa realizar uma inflexão sobre o conceito de território. Existem múltiplas interpretações que, muitas vezes, misturam-se com outros conceitos, tais como espaço e lugar. A despeito dessas múltiplas interpretações, não pretendendemos aqui focar em cada um desses

\footnotetext{
${ }^{4}$ Sobre a ineficácia dos inúmeros acordos firmados pela comunidade internacional, Ferrajoli (2007) complementa: "Se quisermos que tais cartas sejam levadas a sério, como normas e não como declarações retóricas, faz-se necessário que essa falta de garantias seja reconhecida, pela cultura jurídica e política, como uma lacuna, cujo preenchimento é obrigação da ONU e, portanto, dos Estados que a essa aderem. Não estamos pensando de forma alguma num improvável e indesejável governo mundial. (...) pensamos na perspectiva (...) de uma limitação efetiva da soberania dos Estados por meio da introdução de garantias jurisdicionais contra as violações da paz, externamente, e dos direitos humanos, internamente" (FERRAJOLI, 2007, p. 54).
} 
conceitos. Delimitamos território como resultado da ação e da intervenção coletiva humana e institucional num determinado espaço, que se dá de maneira dinâmica e polimórfica, por meio de diferentes interesses, muitas vezes contraditórios e conflituosos, visto como repleto da materialização de subjetividades, simbolismos e culturas dos agentes sociais.

Evocar o conceito de território implica também estabelecer a relação desse com o poder. Conforme Souza (1995, p. 97), o território é definido "como um campo de forças, de relações de poder espacialmente delimitadas e desenvolvidas sobre um espaço", na medida em que o território é impactado pela relação de domínio e apropriação do espaço por instrumentos da ação política e econômica.

Diante de tantas peculiaridades, é oportuno reforçar que o Direito Internacional ainda reverencia o princípio da territorialidade reduzida ao Estado-Nação e atrelado ao da soberania nacional. Contudo, não é mais possível resolver questões de cunho internacional com base na antiga concepção de soberania. Hoje, demandam novos instrumentos tanto de realização de práticas político-econômicas e de gestão de políticas públicas internacionais, quanto do controle transnacional da destruição ambiental e da pobreza.

Atualmente a questão social tornou-se transterritorial e vulnerável aos setores dominados por grupos econômicos globais; e, portanto, aos mais fortes e com mais poder para influenciar um país, um município, um distrito ou um Estado.

Nesse sentido, Pierre Veltz (1996) afirma que a articulação da globalização com regionalizações do ponto de vista geográfico urge, pois a globalização não é o aparecimento de uma rede de unidades perfeitamente independentes, substituíveis e sem ligações com os territórios. O processo de globalização toma formas geográficas muito variadas e como estratégia de domínio da diversidade. Dessa forma, supõe uma articulação fina com as especificidades locais dos mercados e, mais geralmente, com os contextos sociopolíticos globais.

Quando se destaca a intervenção do mundo corporativo (empresas e indústrias) num determinado território, podemos imaginar inúmeras e infinitas externalidades negativas geradas que ultrapassam barreiras e limites territoriais.

Uma situação emblemática de grande intervenção corporativa em cidades é aquela existente nas chamadas company-town ${ }^{5}$ (GARNER; JOHN, 1984). Nesse caso, uma corporação possui uma grande influência e dominação econômica e política,

\footnotetext{
${ }^{5}$ Podemos definir company-town, cidade-company ou cidade-empresa como um clássico modelo em que cidades ou regiões são controladas por uma empresa, com duas perspectivas: de um lado, para suprir com razoável grau de garantia as necessidades de força de trabalho, por meio da fixação dessa pelo fornecimento de moradia. Por outro, estender o domínio da empresa ao âmbito privado dos trabalhadores, por meio de vários mecanismos de imposição de disciplina.
} 
ao mesmo tempo em que possui imenso poder simbólico sobre a população. A corporação, principalmente uma indústria, é capaz de gerar suas próprias geografias e induzir suas condições de crescimento para atrair fatores de produção de que necessita, tais como: ocupação indiscriminada de solos de alta qualidade agrícola; agressões paisagísticas; contaminação e poluição do ar, das águas, do solo, visual e sonora; entre outras externalidades negativas. Esse fato nos leva aos seguintes questionamentos: qual a cota-parte da responsabilidade social da indústria nesse território diante dessa cidade, dos municípios do entorno e do país? De que forma essas externadidades negativas ultrapassam as fronteiras do país e repercutem no planeta? De quem será a responsabilidade transnacional desses impactos?

Enfim, diante dos múltiplos processos de globalização e da importância de outros atores políticos como as cidades, faz-se mister a crítica da soberania do Estado como um poder supremo, que acredita que ele não se deriva de outros e se origina em si mesmo.

\section{Governança transnacional e sustentabilidade}

Na modernidade ocidental, o Estado passou por importantes ciclos de mudanças. A primeira, no século 18, foi o desmonte do Estado Leviatã em nome da nova ordem burguesa e do emergente liberalismo. No século 19, a concepção de Estado Liberal democrático, em confronto com a luta de classes e o socialismo, passou a se relacionar intrinsecamente com o capitalismo liberal que se fortaleceu e se expandiu, com a industrialização, nos países centrais, mesmo que com intensidade e peso diferentes. Posteriormente, no início do século $\mathrm{XX}$, a crise do capitalismo liberal tomou de volta alguns princípios hermenêuticos do Estado Leviatã e, criou os Estados totalitaristas, que felizmente foram derrotados pela democracia.

Depois da Segunda Guerra Mundial, um novo contrato social foi estabelecido pelo Estado liberal e, baseou-se no pressuposto geral de que o Estado-Nação, elo de integração entre os indivíduos. Teria como fundamento atender aos princípios do bem comum e da vontade geral. Nesse contrato social, o Estado "sacrificou" capitalistas individuais - que deixaram de ter algum lucro que tinham antes -, em favor de um melhor funcionamento da sociedade que, no seu conjunto, acabou por fortalecer o próprio capitalismo.

No pós-guerra, com o avanço do crescimento econômico e da capacidade reguladora do Estado nas sociedades capitalistas, formaram-se duas estruturas estatais: o Estado de Bem-Estar Social na Europa e no Canadá e o Estado desenvolvimentista nos países da periferia. O Brasil nunca possuiu um Welfare State no sentido clássico do termo. A experiência brasileira de welfare state se aproximaria do modelo bismarckiano, pelo fato de o Governo Vargas ter oferecido direitos 
trabalhistas e previdenciários ao operariado industrial em troca de reconhecimento do papel do Estado como regulador das relações entre trabalho e capital. Os claros limites do modelo brasileiro pressupõem a construção de um Estado voltado para a tardia industrialização e reprodução da força de trabalho.

$\mathrm{Na}$ chamada "era dourada" dos anos 1950, consolida-se a ideia da responsabilidade do Estado pelo acesso de todos à proteção social, concebida como um direito universal. Portanto, a intervenção do Estado na economia tinha por objetivo garantir as condições de bem-estar social e fortalecer o crescimento capitalista.

No entanto, nos anos 1970, o Estado dá outra reviravolta. Dessa vez quem deu as cartas foi a economia do petróleo. Em 1973, os países árabes da OPEP, em razão da Guerra Yom Kippur, aumentaram o preço do barril em 400\%. Em 1979, a crise no Irã gerou um aumento que chegou a 1.000\%.

Portanto, a partir de meados dos anos 1970, as incertezas passam a dar conta do cenário internacional. A crise do petróleo e a consequente crise fiscal no ocidente gerou um novo sistema mundial de cunho competitivo, expresso pelos processos de globalização, pela retração do Estado e pela emergência da sociedade civil que passou a lutar pelos direitos humanos e sociais. Importa ressaltar que esses movimentos da sociedade civil deixaram de ter um caráter de luta de classe e passaram a ser orientados por reivindicações pós-materialistas, tais como a ecologia, a postura antinuclear, o pacifismo, o sexismo, grupos étnicos, de direitos humanos, entre outros. Esse novo cenário mundial impulsionou também a reestruturação do contrato social do Estado, até então estabelecido entre capital e trabalho.

Diante da transição histórica do capitalismo, as incertezas dos processos da globalização criaram uma tensão nas relações entre Estado e sociedade. Nesse cenário, pudemos observar o reajustamento estatal e societário. Novas formas de solidariedade, diferentes daquelas organizadas pelo Estado no século 19, apareceram envolvendo associações, organizações da sociedade civil e empresas autodenominadas como socialmente responsáveis e articuladas a organizações não governamentais e/ou a organismos públicos, envolvidos em diversos projetos sociais, para além de uma atuação exclusiva do Estado.

A crise fiscal dos anos 1970-1980 impulsionou uma série de propostas das agências multilaterais de financiamento, principalmente as relacionadas ao Banco Mundial e ao Fundo Monetário Internacional. Um conjunto de recomendações envolvia: privatização de empresas estatais, corte nos gastos públicos e sociais e estabilização monetária. As políticas de ajuste a esse receituário supunham também o fim das formas protecionistas de intervenção do Estado, dos subsídios às atividades econômicas e a desregulamentação da economia. Além disso, a forma 
burocrática de administração centralizada no Estado foi criticada por essas agências, por ser considerada como um tipo de gestão rígida e ineficiente do aparato público.

Nessa trajetória, percebemos a importância de forças políticas transnacionais, assim como de mudanças na estrutura das relações internacionais e da soberania dos Estados para o desenvolvimento de uma gestão de políticas públicas em nível transnacional. Nesse ponto, o grande impasse seria o de se definir quem seria essa força política transnacional, buscando evitar o risco de se incorrer em um improvável e indesejável governo mundial ou em um centrocentrismo, que coloca os países centrais e hegemônicos mais uma vez em foco (FERRAJOLI, 2007; SANTOS, 1995).

Como salienta Walzer (2003):

[...] qualquer que seja o acordo hipotético, não poderia ser posto em prática sem acabar com os monopólios políticos dos Estados existentes e centralizar o poder em todo o globo. Por conseguinte, o acordo (ou sua imposição) não serviria de igualdade complexa, porém de igualdade simples - se o poder fosse predominante e amplamente compartilhado - ou de mera tirania - se tivesse sido confiscado, como provavelmente seria, por um conjunto de burocratas internacionais (WALZER, 2003, p. 36).

A atual crise econômica e financeira mundial tem demonstrado que ocorreram e ocorrem inúmeras e significativas fragilidades dos organismos multilaterais internacionais. Eles fracassaram ao tentar somente constranger e/ou sensibilizar o mundo empresarial, por meio de diretrizes voluntárias, a assumirem boas práticas e condutas responsáveis e sustentáveis para com a comunidade, os trabalhadores e o meio ambiente ${ }^{6}$. Vale dizer, junto com Hardt e Negri (2010), que a moderna geografia imperialista em permanente transformação representa mudanças nos próprios modos capitalistas de produção. Nesse sentido, o capital passa a se defrontar com um mundo com novos e complexos regimes de diferenciação, em contínuos processos de desterritorialização e reterritorialização.

Ao final da Conferência das Nações Unidas para o Desenvolvimento Sustentável (Rio+20), foi elaborado um documento final O Futuro que Queremos (ONU, 2012). Em 2012, foi reafirmada a necessidade de mudanças fundamentais nas diretrizes e

\footnotetext{
${ }^{6}$ Acerca da cooperação internacional em matéria ambiental, julgamos oportuno transcrever as reflexões de Edis Milaré (2007), nos seguintes termos: “A cooperação internacional, em matéria ambiental, nada mais é do que o reflexo vivo do reconhecimento da dimensão transfronteiriça e global das atividades degradadoras exercidas no âmbito das jurisdições nacionais, cujas sequelas podem alcançar muito além do previsto. Isso significa que o princípio da cooperação internacional reflete as tendências ditadas pelo conjunto da ordem internacional contemporânea, da interdependência crescente entre as nações, à procura de um equacionamento e da solução de problemas que transcendem as fronteiras nacionais e a geopolítica tradicional” (EDIS MILARÉ, 2007, p. 1164).
} 
comportamentos institucionais e humanos que continuam impactando de forma negativa os sistemas sociais, econômicos e ambientais dos territórios do planeta.

Esse documento, assinado por diversos chefes de Estado e governos, conclamou a urgência da promoção da sinergia de esforços para melhorar a resiliência e diminuir a vulnerabilidade social e econômica de comunidades. Foi acordado que o compromisso de todos é de fundamental importância para a diminuição das desigualdades entre o Norte e o Sul, e para a erradicação da pobreza no contexto de uma população mundial em crescimento.

Nesse contexto, pode-se observar que o referido documento está alinhado e conectado com a Declaração do Milênio das Nações Unidas e com os Objetivos do Desenvolvimento do Milênio, assumidos pelos membros das Nações Unidas, em setembro de 2000. Essa declaração foi criada com a proposta de sintetizar acordos internacionais, alcançados em várias cúpulas mundiais ao longo dos anos 1990.

Importa ressaltarmos a conexão de propósitos entre as Metas do Milênio e os propósitos do evento Rio+20. Desde 2000, esses objetivos/metas passaram a ser discutidos e expandidos nas agendas internacionais, bem como em âmbito nacional e local, envolvendo entidades governamentais, a sociedade civil e instituições empresariais, no intuito de se buscar formas de inserir as referidas metas nas estratégias de gestão de governança corporativa de muitas organizações.

Observa-se um avanço normativo no documento final da Rio+20, em relação à declaração das Metas do Milênio. No relatório O Futuro que Queremos emerge a preocupação com um marco institucional regulatório global para o desenvolvimento sustentável. O documento aponta a importância desse marco institucional, a fim de responder de forma coerente e eficaz aos desafios atuais e futuros, reduzindo as lacunas da agenda internacional de desenvolvimento sustentável.

Existe um relativo consenso de que para promover a sustentabilidade do planeta seria de fundamental importância uma atuação efetiva da governança local, subnacional, nacional, regional e mundial que represente as opiniões e os interesses de todos.

Contudo, o próprio documento, assim como os seus antecedentes, reconhece (no parágrafo 268) que a função apropriada dos governos em relação à promoção e regulação do setor privado varia entre os países, de acordo com as circunstâncias nacionais. Nesse sentido, tal documento esboça um dilema para se dirimir as assimetrias entre os países do Norte e do Sul.

Portanto, será necessária a adoção de novas medidas e ações eficazes, de conformidade com a reconstrução do Direito Internacional, para eliminar as 
assimetrias e os obstáculos, principalmente dos territórios mais frágeis e vulneráveis; ou seja, os países pós-colonizados, da periferia do sistema mundo.

O desafio atual está em se construir um compromisso e um consenso para a construção de uma gestão de políticas públicas concertadas por meio de uma governança inteligente, capaz de estabelecer uma via intermediária entre o Ocidente e o Oriente. A intenção é delegar o poder de modo eficaz, envolvendo os cidadãos em questões que os afetam diretamente, de modo a conciliar a democracia informada e a meritocracia responsável (BERGGRUEN; GARDELS, 2012).

A questão, no âmbito de busca de alternativas para além do liberalismo homogeneizador, não seria, conforme Walzer (2003), perguntar-se "O que os indivíduos racionais escolheriam em situações universalizantes de tal tipo?", mas, pelo contrário, identificar os entendimentos de fato compartilhados, a partir das localidades, e inferir: "O que escolheriam indivíduos como nós, situados como nós, que compartilham uma cultura e estão decididos a continuar compartilhando?" (WALZER, 2003, p. 4).

A atual crise econômica e financeira demonstra a fragilidade das "boas intenções" e dos pactos globais, de base voluntária, em relação ao tema da sustentabilidade e da responsabilidade social das empresas. Por outro lado, tem também mostrado a importância das decisões infraestatais para minimizar os efeitos da crise. Diante disso, afirmamos que o árbitro da governança transnacional pode estar nas mãos de lideranças internacionais e dos movimentos sociais, que não se distingue nem se separa da sociedade civil. Tratam-se aqui de agentes reguladores transnacionais das externalidades corporativas e financeiras, que deveriam ser agentes de fora dos aparelhos dos Estados, interessados na justiça social e ambiental.

Nesse caso, a gestão da governança do Estado nacional precisa ser transcodificada para o parâmetro da territorialidade transnacional, na medida em que o que está em jogo é a relação de poder entre os Estados mais fortes (Norte) e os mais frágeis (Sul). Como ambos estão expostos ao mesmo aumento de riscos econômicos, tecnológicos e socioambientais, é necessária uma governança transnacional. Que ela seja resultante da luta daqueles que têm a percepção de que esses riscos, apesar de não se redistribuírem igualmente, afetam todo o planeta, todos os Estados e, portanto, todos os territórios e os seres que o habitam.

Conforme Amartya Sen e Kliksberg (2010), as injustiças sociais e a distribuição dos benefícios na economia global dependem, entre outras coisas, de arranjos institucionais globais adequados ao desenvolvimento e às oportunidades globais equitativas: 
Há uma necessidade urgente de reformar os arranjos institucionais - além dos nacionais - para se poder superar tanto os erros de omissão como os de ação que tendem a dar aos pobres de várias partes do mundo oportunidades tão limitadas (SEN; KLIKSBERG, 2010, p. 32).

O estabelecimento de uma governança transnacional pode ser o resultado da constatação racional, mesmo que limitada, de que a crise afeta a todos, em alguma medida, em alguma dimensão e em algum momento.

\section{À guisa de considerações finais}

No fim do século 20, vimos que o Estado perdeu parte de sua soberania econômica frente às multinacionais e ao contexto da globalização, tais como os fluxos globais de capital, de comércio, de gestão, de informação, da rede complexa do crime organizado, de problemas ambientais e da insegurança cidadã. O aparelho do Estado centralizador, confinado por tecnocratas e/ou empresários, excluiu a participação da sociedade civil em suas decisões; e, associado com a crise fiscal dos anos 1970, acabou por gerar perda de sua credibilidade e governabilidade.

Dessa forma, podemos concluir que os diferentes ciclos do Estado liberal ocidental emanam da ambivalência dos propósitos do Estado: por um lado, tem como função conciliar dinamicamente os requisitos da acumulação capitalista; e, por outro, preservar a legitimidade de seu poder, por meio de seu papel enquanto representante dos interesses gerais e comuns da sociedade como um todo. Nesse sentido, a tomada de decisões pelos governos se baseará na tentativa de estabelecer um equilíbrio dinâmico entre os elementos constitutivos dos interesses da acumulação de capital e dos interesses dos trabalhadores.

No final do século 20, vivenciamos a reengenharia do Estado com proposta neoliberal de desmonte do projeto da atividade social estatal como ator central. Emerge uma nova forma de gestão pública estratégica e gerencial, ainda em curso, onde é colocada a ideia de uma coordenação nova e de redes de parcerias como solução de problemas que o Estado centralizador não consegue responder.

Diante da atual complexidade social, quando a liberdade é envolvida por uma pluralidade de atores, o Estado parece impossibilitado de atender a todos os riscos sociais. Dessa forma, fica difícil adotarmos a concepção centralizadora da ordem pelo Estado, ainda que tenhamos em mente que um Estado democrático deva zelar pela paz e responder adequadamente aos deveres que the cabem.

A antiga concepção de soberania e as opções de desenho institucional monístico que tenta garantir a ordem e a coesão social estão obsoletas. Para o século 21 , não há como nos basear em soluções únicas vindas do Estado, ou do mercado, 
ou da comunidade. Qualquer desenho institucional que seja síntese de mercadoEstado, Estado-comunidade, ou comunidade-mercado tende a ignorar e destruir as contribuições que os outros (ou o outro) têm a dar. Cada um desses três componentes (Estado, mercado e comunidade) gera padrões correspondentes de ordem social, na medida em que cada um deles tem papéis variáveis que não se limitam em si mesmos. Dessa forma, torna-se evidente a autolimitação de cada uma dessas esferas e de uma sintonia fina e processual, crítica e flexível entre os três componentes (OFFE, 2000).

Importa, no cenário atual de desafios e dilemas na gestão pública para o século 21 , concebermos uma nova forma de pensar a responsabilidade coletiva, que supere a polarização entre responsabilidade individual e a responsabilidade social capturada pelo Estado, típica do pensamento moderno.

Essa nova forma de responsabilidade, de tradução coletiva, só poderá ser alcançada a partir de mudanças hermenêuticas e institucionais abrangentes para a promoção da igualdade e da liberdade, na direção de relações mais democráticas, isto é, nem manipulativas, nem hierárquicas.

O Brasil, por exemplo, sempre almejou uma importante inserção internacional, principalmente nas últimas décadas. Teve a sua política externa direcionada para uma cooperação técnica entre os países em desenvolvimento, em especial nos países lusófonos da África. No âmbito das Nações Unidas, a Cooperação Sul-Sul (United Nation Office for South-South Cooperation) é uma estratégia internacional com uma ampla estrutura de colaboração entre os países do Sul nas áreas política, econômica, social, cultural, ambiental e técnica. Pode envolver dois ou mais países em desenvolvimento por meio de acordos bilaterais, regionais, subregionais ou interregionais. Os países em desenvolvimento compartilham conhecimentos, habilidades, competências e recursos para atender às suas metas de desenvolvimento, por meio de esforços concertados ${ }^{7}$.

Essa cooperação técnica entre países do Sul pressupõe a construção de uma sinergia das relações internacionais orientada pela solidariedade, consenso e equidade, principalmente na transferência de políticas públicas exitosas entre os países. E o Brasil, a despeito das incongruências domésticas, teve uma relativa participação nesse contexto. Visto assim, podemos vislumbrar a importância da participação do Brasil como liderança do Sul para influenciar uma agenda de gestão pública na concepção de uma governança transnacional.

\footnotetext{
${ }^{7}$ United Nations Office for South-South Cooperation - Disponível em: <http://ssc.undp.org/content/ssc/about/ what_is_ssc.html.>. Acesso em 24 out. 2016.
} 
Importa ressaltar que a transnacionalidade não é um fenômeno novo. Ela representa uma perspectiva nova para o século 21. Nesse sentido, o Brasil poderia ser uma liderança importante quando capaz de agregar, não somente organismos multilaterais tradicionais, mas também organizações não governamentais e movimentos cívicos. É emblemático que a Rio 92 e a Rio+20 tenham ocorrido no palco brasileiro.

Portanto, em alguma medida, tem brotado um novo pensamento em busca de um consenso de novas políticas públicas em nível global. Importa, agora, que seja traçado um desenho de uma nova agenda transnacional no campo da gestão das políticas públicas por meio de blocos, coalizões e parcerias com o Sul, para superarmos as mazelas sociais e ambientais transfronteiriças. Nesse sentido, é necessário conclamarmos uma sinergia entre gestores e policymakers para construírem um pensamento heurístico criativo e inovador que possa transpassar questões domésticas, que também atingem de maneira similar a ordem global.

É um esforço em que será necessário com uma mobilização coletiva de lideranças que lancem propostas que ultrapassem os seus entraves nacionais, subnacionais e locais e, que consiga alcançar dimensões transfronteiriças por meio de um debate genuíno. Para tanto, fazer-se-á necessário buscar experiências positivas em diversas outras regiões do Planeta. Sejam aquelas que ainda estão em grau de desenvolvimento periférico ou semiperiférico do sistema mundo capitalista, tanto quanto experiências do aprendizado do mundo central e desenvolvido. A troca e o intercâmbio de experiências são de suma importância para que se construa uma nova forma de gestão pública para o século 21, pautada na eficiência e na sustentabilidade social mais ampla.

É nessa trajetória de imaginação política para a gestão pública do século 21 que nos concentramos neste artigo: a de uma concepção epistemológica quântica para a construção de uma governança transnacional, na medida em que os problemas de nosso mundo atual estão entrelaçados e são transfronteiriços.

Vimos que toda e qualquer intervenção tem efeitos em cadeia. Os efeitos podem ser ínfimos ou perdurarem no tempo e, na maioria, não se tem qualquer ideia da dimensão desses efeitos. Essa é a complexidade da sociedade global. Em suma, todos nós somos responsáveis pelas consequências de nossos atos, mas também pelos dos outros, na medida em que estão a cargo ou ao cuidado de cada um.

As externalidades negativas não afetam apenas o limite do território nacional, mas o território planetário. Nesse sentido, precisamos encontrar uma convergência de forças que atue no fortalecimento de uma efetiva gestão da governança transnacional, na medida em que existem sociedades civis e instituições frágeis para, sozinhas, exercerem o controle regulamentar em prol do bem-estar coletivo da população local. 
Importa que lideranças sociais globais procurem perguntas e respostas fortes e críticas, fundamentadas no paradigma de que o desenvolvimento social e humano deve ser construído de maneira pragmática na dimensão da dignidade e da justiça social. Oxalá que os problemas locais sejam colocados transversalmente no palco do debate de uma governança transnacional efetiva, participativa e democrática.

Acrescentamos que a potencialidade da formulação de uma agenda global que alie os princípios da governança à gestão pública deverá atentar para o reconhecimento da pluralidade e dos possíveis conflitos de interesses dos principais agentes e atores. As desejadas alterações locais, nacionais e globais dependem da formulação de um projeto coletivo de uma governança de gestão e concertação transnacional para o século 21. Enfim, "Não há nada como o sonho para criar o futuro. Utopia hoje, carne e osso amanhã" (VICTOR Hugo, em Os Miseráveis, 1872).

\section{Referências bibliográficas}

ARAÚso, Izabela Viana de. A governança global e a atuação das redes internacionais de cidades. $3^{\circ}$ Encontro Nacional ABRI, 2011.

BERGgruen, Nicolas; GARDELS, Nathan. Governança inteligente para o século XXI uma via intermediária entre o Ocidente e o Oriente. São Paulo: Objetiva, 2012 .

BRESSER PEREIRA, L.C. Reforma do Estado para a Cidadania. A reforma gerencial brasileira na perspectiva internacional. SP: Editora 34, 1998.

CAMPIlongo, Celso Fernandes. A soberania dividida. In: Ferrajolı, Luigi. A soberania no mundo moderno: nascimento e crise do Estado nacional. São Paulo: Martins Fontes, 2007.

CASTELls, Manuel. Para o estado-rede: globalização econômica e instituições políticas na era da informação. In: PResser Pereira; Wilheim; SOLA, L. (Orgs.) Sociedade e estado em transformação. Brasília: ENAP e São Paulo: Editora UNESP e Imprensa Oficial de São Paulo, 2001.

COASE, R.H. The nature of the firm. Economica, Blackwell Publishing, v. 4, no 16, 1937.

CORREIA, Telma de Barros. De vila operária à cidade-companhia: as aglomerações criadas por empresas no vocabulário especializado e vernacular. Revista Brasileira de Estudos Urbanos e Regionais, n. 4, p. 83-96, 2001.

COSTA, Maria Alice Nunes. Teias e Tramas da Responsabilidade Social. Rio de Janeiro: Editora Apicuri, 2011.

Crawford, Margaret. The 'New' Company Town. Perspecta, v. 30, Settlement Patterns, p. 48-57, 1999.

DALLABRIDA, Valdir Roque. Desenvolvimento e governança territorial: um ensaiopreliminar sobre a necessidade da regulação no processo de gestão do desenvolvimento. Redes, Santa Cruz do Sul, v. 15, n. 3, p. 165 - 186, set./dez. 2010. 
DiniUs, Oliver J.; VergarA, Angela (ed.). Company towns in the Americas: landscape, power, and working-Class Communities. Athens, GA.: University of Georgia Press, 2011.

DINIZ, Eli. Governabilidade, democracia e reforma do estado: os desafios da construção de uma nova ordem no Brasil dos anos 90. In: Revista de Ciências Sociais/Dados, Rio de Janeiro. IUPERJ, v. 38, no 3, 1995.

DOMINGUES, J. M. Interpretando a modernidade: imaginário e instituições. Rio de janeiro: Fundação Getúlio Vargas, 2002.

FerRAJoli, Luigi. A soberania no mundo moderno: nascimento e crise do Estado nacional. São Paulo: Martins Fontes, 2007.

GARnER, John S., ed. The Company town: Architecture and Society in the Early Industrial Age. New York: Oxford University Press US, 1992.

GARNER, John.. The model company town: Urban Design through Private Enterprise in Nineteenth-Century New England. Amherst: University of Massachusetts Press, 1984.

GRAU, Nuria C. Repensando o público através da sociedade: novas formas de gestão pública e representação social. Rio de Janeiro: Editora Revan. Brasília: ENAP, 1998.

GREEN, Hardy. The company town: the industrial edens and satanic mills that shaped the American economy. New York: Basic Books, 2010.

GuERRA, Isabel. Cidadania, exclusões e solidariedades: parodoxo e sentidos das novas políticas sociais. Revista Crítica de Ciências Sociais, Coimbra, Centro de Estudos Sociais, n. 63, 2002.

HABERMAS, J. A nova intransparência: a crise do estado de bem-estar social e o esgotamento das energias utópicas. Novos Estudos CEBRAP, São Paulo, n.18, set. 1987.

HARDT, Michael; NegRI, Antonio. Império. Tradução de Berilo Vargas. 9a ed. Rio de Janeiro: Record, 2010.

Hugo, Victor. Os Miseráveis. Publicado em 1872. Domínio Público.

LECHNER, Norbert. Tres formas de coordinación social. Revista de la CEPAL, n. 61, abril 1997.

MILARÉ, Édis. Direito do ambiente. São Paulo: Revista dos Tribunais, 2007.

OfFE, Claus. A atual transição da história e algumas opções básicas para as instituições da sociedade. In: BRESSER PEREIRA, L. C. et al. (Orgs.). Sociedade e estado em transformação. São Paulo: Unesp. Brasília: Enap e Imprensa Oficial, 2000.

ORgANIZAÇÃO DAS NAçÕES UNIDAS (ONU). Conferência das Nações Unidas sobre o Desenvolvimento Sustentável. Relatório Final da Rio +20: The Future We Want. Brasil: Rio de Janeiro, 2012.

REIS, José. Governação e territórios na Europa: hipóteses sobre um sub-federalismo europeu. In: RiBEIRo, Maria Manuela Tavares (coord.). Ideias de Europa: que fronteiras? Coimbra: Quarteto, 2004, p. 13-27.

Rosanvallon, Pierre. A Crise do Estado-Providência. Brasília: UnB. Goiânia: UFG, 1997. 
SANTOS, Boaventura de Sousa. O Movimento Democrático Transnacional. Visão (Portugal), 5 de Outubro de 2000.

SANTOS, Boaventura de Sousa. Beyond neoliberal governance: the world social forum as subaltern cosmopolitan politics and legality. In: SANTOS, Boaventura de Sousa; Rodríguez-Garavito, César (orgs.) Law and globalization from Below: towards a cosmopolitan legality. Cambridge: Cambridge UP, 2005.

SAntos, Boaventura de Sousa. Pela mão de Alice: o social e o político na pósmodernidade. São Paulo: Ed. Cortez, 1999.

SANTOS, Milton. Território, globalização e fragmentação. São Paulo: Hucitec, 1994.

SeN, Amartya; KlikSBERG, Bernardo. As pessoas em primeiro lugar: a ética do desenvolvimento e os problemas do mundo globalizado. São Paulo: Companhia das Letras, 2010.

SouzA, M. L. O território: sobre espaço e poder, autonomia e desenvolvimento. In: Castro, I. et al. (org.) Geografia: conceitos e temas. Rio de Janeiro: Bertrand Brasil, 1995.

United nacion Development Programme (UNDP). Reconceptualising governance, discussion paper 2, management development and governance division, bureau for policy and programme support. New York, jan. 1997.

VELTZ, Pierre. Mondialisation, villes et territoires: l'économie d'archipel. Paris: PUF, 1996.

WALzer, Michael. Esferas da justiça: uma defesa do pluralismo e da igualdade. São Paulo: Martins Fontes, 2003.

WELLMAN, Barry. Strutural Analysis: from method and metaphor to theory and substance. In: Wellman, Barry; Berkowitz, S. D. Social Strutures: a network approach. Cambridge: Cambridge University Press, 1991.

WILLIAMSON, O.; WINTER, S. (orgs.) The nature of the firm. New York, Oxford: Oxford University Press, 1991.

Maria Alice Nunes Costa

É Pós-doutora em Sociologia pelo Centro de Estudos Sociais da Universidade de Coimbra (2007-2011, Portugal); Doutora em Planejamento Urbano e Regional pela Universidade Federal do Rio de Janeiro (IPPUR/UFRJ, 2006), com Estágio Doutoral na Faculdade de Economia da Universidade de Coimbra (2004-2005). É Mestre em Ciência Política pela UFF (2002) e Bacharel e Licenciada em Ciências Sociais pela Universidade Federal Fluminense (1988). Atua como professora da Universidade Federal Fluminense no Departamento de Artes do Instituto de Arte e Comunicação Social (IACS) e Professora do Programa de Pós-Graduação em Sociologia e Direito da Universidade Federal Fluminense (PPGSD/UFF). É Pesquisadora Associada do Centro de Estudos Sociais (CES, UC, Portugal) e do Instituto de Estudos do Trabalho e Sociedade (IETS, Rio de Janeiro). É líder do Grupo de Pesquisa LADER (Laboratório de Políticas Públicas, Governação e Desenvolvimento Regional). Contato: alicecosta.rj@uol.com.br

Wagner dos Santos Ramos

É Graduado em Administração pela Universidade Federal Fluminense (2009). Possui MBA em Organização e Estratégia pela Escola de Engenharia da Universidade Federal Fluminense (2011) com ênfase em Responsabilidade Social. É Mestre em Sistemas de Gestão pela Universidade Federal Fluminense (2013), com linha de pesquisa em Sustentabilidade e Responsabilidade Social. Desde 2009. Atua profissionalmente como Analista de Projetos Institucionais da Federação das Indústrias do Estado do Rio de Janeiro - Sistema Firjan. Contato: wagner.sramos7@gmail.com 
Daniela Juliano Silva

É Doutoranda em Sociologia e Direito da Universidade Federal Fluminense, Mestre em Sociologia e Direito pelo PPGSD/UFF. É Graduada em Direito pela Universidade Federal de Uberlândia/MG e Especialista em Gestão e Manejo Ambiental pela Universidade Federal de Lavras/MG, com MBA em Direito Empresarial pela Fundação Getúlio Vargas - FGV/RJ. É Especialista em Planejamento, Implementação e Gestão em Educação a Distância (PIGEAD) pela Universidade Federal Fluminense. Professora no Grupo Lusófono (FAP/RJ). Contato: danjulsil@yahoo.com

Mariana Devezas Rodrigues Murias de Menezes

Professora Assistente na Universidade Federal Fluminense. É Doutoranda no Programa de Pós-Graduação em Sociologia e Direito pela Universidade Federal Fluminense (PPGSD). É Mestre em Ciências Jurídicas e Sociais pela Universidade Federal Fluminense (PPGSD) e Especialista em Direito Processual pela Universidade Federal Fluminense. É líder do Grupo de Pesquisa GEPPIC (Grupo de Estudos em Políticas Públicas, Instituições e Controles). Contato: mari.devezas@gmail.com 